\title{
Victor Hugo et la langue, actes du colloque de Cerisy, août 2002, textes réunis par Florence Naugrette et Guy Rosa
}

\section{Jean-Claude Fizaine}

\section{(2) OpenEdition}

Journals

\section{Édition électronique}

URL : https://journals.openedition.org/studifrancesi/26538

DOI : 10.4000/studifrancesi.26538

ISSN : 2421-5856

Éditeur

Rosenberg \& Sellier

\section{Édition imprimée}

Date de publication : 1 avril 2007

Pagination : 194

ISSN : 0039-2944

\section{Référence électronique}

Jean-Claude Fizaine, «Victor Hugo et la langue, actes du colloque de Cerisy, août 2002, textes réunis par Florence Naugrette et Guy Rosa », Studi Francesi [En ligne], 151 (LI | I) | 2007, mis en ligne le 30 novembre 2015, consulté le 23 novembre 2021. URL : http://journals.openedition.org/studifrancesi/ 26538 ; DOI : https://doi.org/10.4000/studifrancesi.26538

Ce document a été généré automatiquement le 23 novembre 2021.

\section{cc) (†) $\odot$}

Studi Francesi è distribuita con Licenza Creative Commons Attribuzione - Non commerciale - Non opere derivate 4.0 Internazionale. 


\section{Victor Hugo et la langue, actes du colloque de Cerisy, août 2002, textes réunis par Florence Naugrette et Guy Rosa}

Jean-Claude Fizaine

\section{RÉFÉRENCE}

AA. VV., VICTOR HUGO et la langue, actes du colloque de Cerisy, août 2002, textes réunis par Florence NAUGRETTE et Guy ROSA, Bréal, 2006, pp. 574.

1 Le Groupe Hugo, de l'Université de Paris VII, s'est chargé d'organiser à Cerisy le rituel colloque commémorant le bicentenaire de la naissance de Victor Hugo. La présentation de Guy ROSA (pp.15-31) nous aide, avec fermeté, à nous faire une idée claire de la problématique choisie et des grands enjeux de la critique hugolienne aujourd'hui.

2 La première section, sous le titre «Où l'on voit Hugo écrire», s'attache à l'innovation apportée par Hugo d'un «travail artistique sur la langue», selon l'expression de Judith WULF (pp. 169-188), qui interdit de l'enfermer dans les frontières d'un mouvement littéraire ou d'une époque historique. Ainsi Myriam RomAN (pp. 35-51) peut-elle citer à la fin de son intervention sur Le Dernier Jour d'un condamné, comme pour la mettre en exergue du colloque tout entier, la phrase célèbre de Roland Barthes qui a excepté Hugo, seul des romantiques, de l'appartenance à une tradition rhétorique.

La seconde section, «Où l'on entend parler Hugo et ses personnages», passe en revue les genres divers - pamphlets, mémoires, théâtre, romans - pour donner à entendre «le melting pot de paroles» que composent les dialogues, notamment romanesques, dans un disparate soigneusement calculé. 
Ce travail sur les langages n'a cessé de choquer, comme le soulignent les communications, assez divertissantes, regroupées sous le titre «Où l'on juge la langue de Hugo». Titre ironique: il ne s'agit pas, pour ses contemporains, de le juger, mais de louer, caricaturer ou blâmer. D'où ce curieux paradoxe: la question de la langue révèle le secret d'une emprise sans exemple, exercée par un auteur sur ses ennemis autant et presque plus que sur ses disciples déclarés, comme le souligne Martie-Françoise MELMOUX-MONTAUBAN (pp. 363-384).

5 C'est à la confrontation de Hugo avec des univers linguistiques ou sémiotiques autres que s'attache donc la partie suivante, «Où l'on passe d'un art à un autre». Car l'atelier de Hugo doit se concevoir comme une immense forge, où divers matériaux sont puissamment amalgamés dans une unité originale. Son œuvre se développe par une série de confrontations ou de rencontres avec des univers linguistiques autres. Il peut s'agir de langues appartenant à des genres différents, comme dans le cas du mélodrame, d'éléments linguistiques provenant d'autres époques littéraires, comme les apports du Moyen-Âge et de la Renaissance. Ou encore l'œuvre s'ouvre aux autres arts, soit que le livre annexe, si l'on peut dire, l'architecture, soit que la musique se saisisse du texte qui, dans ce nouveau milieu, continue de faire vibrer sa richesse de séduction et de suggestion, comme le montre la belle communication d'Hervé LACOMBE (pp. 473-485).

6 La voie est ainsi ouverte pour la dernière section, «Où l'on apprend ce que c'est que la chose appelée "langue"», qui tente une synthèse, autour de deux paradoxes centraux définis par le poète lui-même théorisant la double nature de la poésie qui, selon un texte de William Shakespeare, "a deux oreilles, l'une qui écoute la vie, l'autre qui écoute la mort», c'est-à-dire "le problème muet, l'immense silence, d'un sens inexprimable et terrible». La conscience qu'avait Hugo des implications historiques et politiques des problèmes de langue est mise en évidence dans la communication de Franck LAURENT (pp. 525-549). Mais comment construire une œuvre qui fasse écho aux rumeurs, aux clameurs, aux croyances, aux utopies dont les hommes vivent sans s'asservir à la langue où se dépose tout ce brouhaha? La critique aussi a deux oreilles. L'une, celle d'Alain VAILLANT (pp. 485-508), retrouvant avec une brutalité provocante la plus ancienne tradition critique, ne veut entendre dans ce langage créé par l'auteur à la mesure de ses besoins qu'un babil à sa propre fin, dont le fracas ne recouvre que du vide. L'autre, représentée notamment par Françoise CHENET-FAUGERAS (pp. 509-524), est attentive à la présence, très sensible en certains lieux de l'œuvre, du silence qui l'habite, comme une crypte sous la cathédrale.

7 On regrettera quelques défaillances typographiques ou orthographiques (p. 7 dans le sommaire, 24, 34, 198, 367, 450, 512, 528 note 7). Une docte communicante réussit (par excès d'émotion?) à accumuler trois fautes d'orthographe dans une citation de deux des plus émouvants octosyllabes des Contemplations (p. 98).

8 Tel quel, ce colloque remplit son rôle, à l'aube du xxI siècle, non seulement de faire un bilan du travail effectué, mais de tracer des voies pour l'avenir, en soulignant au passage combien les problèmes posés par l'œuvre de Victor Hugo sont encore et toujours les nôtres. 